\title{
Inequality of Cameroonian Households: An Analysis Based on Shapley-shorrocks Decomposition
}

\author{
Chameni Nembua Célestin ${ }^{1} \&$ Miamo Wendji Clovis ${ }^{2}$ \\ ${ }^{1}$ University of Yaoundé II, Faculty of Economics and Management, Department of Quantitative Methods, Yaoundé, \\ Cameroon \\ ${ }^{2}$ University of Dschang, Faculty of Economics and Management, Department of Political Economic Analysis, \\ Yaoundé, Cameroon \\ Correspondence: Miamo Wendji Clovis, University of Dschang, Faculty of Economics and Management, \\ Department of Political Economic Analysis, P.O BOX 604 Yaoundé, Cameroon. Tel: 237-99-329-706. E-mail: \\ c_miamo_w@yahoo.fr
}

Received: March 13, 2012

Accepted: April 6, 2012

Published: June 1, 2012

doi:10.5539/ijef.v4n6p149

URL: http://dx.doi.org/10.5539/ijef.v4n6p149

\begin{abstract}
The objective of this study is to explain the evolution of inequality of consumption expenditures of households in Cameroon over the period 1996-2007. To achieve this, we use the Shapley-Shorrocks decomposition of inequality by subgroups and by sources of income / expenses. The application of this method to data from Cameroon shows that expenditure on food and housing explains inequality by sources, while the expenditure distribution is much more unequal in households' headed by a man in urban area and slice aged between 31 and 50 regarding the decomposition subgroup.
\end{abstract}

Keywords: inequality, decomposition, sources, subgroup

JEL Classification: D63, I31, I32

\section{Introduction}

Income inequalities exist for centuries now. They were amplified with the industrial revolution of the $18^{\text {th }}$ century, and this phenomenon has increased since this date (Bourguignon and Morrison, 2002). For the past years, studies on this phenomenon are marked by a social dimension of development in economic research. In this regards, questions on inequalities and poverty fuel more and more debates on the determinants of this phenomenon, as well as its link with growth and redistribution in order to identify the causes of income deprivation that some social categories undergo.

The phenomenon calls attention in Africa as a whole and Cameroon in particular. In fact, the Gini index calculated on per capita expenditure based on a purchasing power parity passed from 0.427 to 0.472 (Fambon, 2006). Cameroon, one of the countries admitted to the Heavily Indebted Poor Country Initiative (HIPCI) is not indifferent. According to 1996 and 2001 Cameroon Household Consumption Surveys (ECAM I and II), the ratio of poverty is still high even if a decrease is observed between 1996 and 2001 where this rate passed from 0.53 to 0.42 respectively, main inequality indices also decreased in this period.

This way, the squared indices of the coefficient of variation and entropy show that in 2001 income distribution parted a bit from equalitarian than in 1996, passing respectively from 1.2559 to 1.5230 for the first, and from 0.4579 to 0.4936 for the second. These results indicate that inequalities are increasing instead of decreasing. However, we observe a drop in the Gini coefficient, passing from 0.4955 to 0.4512 (Fambon, 2005; Baye, 2003; Chameni, 2005, 2008; Cameroon Household Consumption Survey report, 1996, 2001).

The inequality in question here is the inequality of income/expense. Despite the contributions of multidimensional analysis in explaining the well-being, income remains an important factor that conditions the acquisition of other attributes of households (Walzer, 1995) and will be used to describe dispersion of household's expenditures. More, Understanding the mechanism that surrounds the lack of income is vital to understand the type of deprivation that can generate and the different forms of poverty that emerge. Since the literature reveals a decrease in the Gini indicator over the period 1996-2001, which is consistent with the reduction of income poverty indicator, it would be important to look at the evolution of this indicator, in order to explain these inequalities according to socio-demographic characteristics of households in Cameroon over the period 1996-2007. This is the objective we set ourselves in framework of this analysis. 
To achieve this, we would resort to decomposition approaches and more specifically, the shapley-shorrocks approach that decomposes total income inequality in terms of subgroup and source income inequality. This method integrates attractive properties and opens easily to experimentation (Shorrocks, 2012).

The structure adopted allows us to present the literature on the understanding of the concept of inequality in economics (2). A review of the decomposition approaches (3) will allow us to introduce the Shapley-Shorrocks decomposition (4). The approach is applied to decompose inequalities of consumption expenditure (proxi of income) of Cameroonian households in the period 1996-2007 (5).

\section{An Overview of Socio-economic Inequalities}

Inequalities in living conditions existed between social classes and within these classes (Tocqueville, 1835-1840). Studies on the evolution of the phenomenon of global inequality since then have shown that they have evolved since the $17^{\text {th }}$ century oscillating before knowing a rise dramatically since the early 1980s (Bourguignon and Morrison, 2002). Even in the most egalitarian societies, age and sex - criteria which are themselves beyond the possibilities of individual influence - note the differences that give rise to cultural interpretations and role assignments, positions, courses specific. These interpretations and attributions are not only differences (identity, activities, clean spaces), but also of inequality in economic, social, autonomy, power.

Socioeconomic inequality refers to differential access to economic and social assets. They are usually the result of a malfunction of the process of social mobility regulating access to favorable or unfavorable situations, stabilization or discrimination (social fragmentation). These elements are usually based on easily identifiable assets and are beyond the influence of involved persons: in particular social background (parental status), ethnicity, nationality, region, and especially sex. What is a "good" in the sense of this definition can vary in time and space, between societies and cultures as well as between subsets of the same company for a specified period, the critical importance of such property from the dominant values and the organization of society at that time. The industrial and postindustrial societies are market, hence the centrality of goods such as income, property, professional position and training (Lemel, 1991).

Inequalities can take several forms, one can distinguish between economic inequality, social and cultural, political and even ethical inequality. Each of these forms may include other specific subject of another hierarchy. Such a classification gives a multidimensional inequality. Thus if there is a similarity between the dimensions described in the analysis of inequality and poverty, it would be possible to link the two concepts to see how they interact and how policies against the poverty can reduce inequality and vulnerability in the long term. In our study, we focus in particular to traditional monetary inequality. It refers to differences between households, individuals and social groups in terms of income or consumption. It is measured by indicators such as the Gini coefficient, the Theil index of the log-variance, etc. (Dubois, 2000).

Socioeconomic inequalities refer to different realities which it is not always possible to determine with certainty the origins; they do not automatically give rise to disputes or conflicts of redistribution. They are challenged if they are not considered legitimate, hence the need, often felt by the wealthy, reduces the visibility of their social privileges or to give them justification. It is sometimes easy to conceal his/her income or expenditure; it is easy to do so by regarding the other indicators of well-being related to housing, education or employment. The analysis of inequalities arising from the possession of these attributes is therefore useful as socio-economic inequalities can challenge political democracy when their legitimacy is lacking in the long-term, hence the need to identify the causes for reduction.

\section{Inequalities Analysis: Decomposition Approaches}

The literature relative to the research of the determinants of income inequalities constitutes an important scope of study for economists, and it is more and more traditional to use some indices with the aim to decompose global inequality between the different variables. The literature review on the application of these analyses permits us to distinguish three (3) main categories of decomposition.

The first category concerns the case where interest is on population sub-groups as gender, age, religion, place of residence, etc. (Bourguignon, 1979; Cowell, 1980; Shorrocks, 1980, 1984; Chameni, 2005(Note 1). The second category concerns the case where the different components of total income/expenditure are examined. Here we attempt to identify the level of total income/ expenditure inequality and thereafter, to identify the contributions of the different components of income in accountable for an observed global level of income (Rao, 1969; Fei, Ranis, and Kuo, 1978; Pyatt, Chen, and Fei, 1980; Shorrocks, 1982; Chantreuil and Trannoy 1999).

The third category concerns the combination of the two uppermost categories, which permits to obtain the methods of simultaneous decompositions of inequality indices (by population sub-groups and by income/expenditure 
sources). This method is based on the 'natural' decomposition of income (Shorrocks, 1982). This way, the relative contribution of total income/expenditure inequality is independent of the inequality index chosen (Mussard, 2004, 2008; Chameni, 2008).

Despite the extended use of these decomposition techniques, Shorrocks $(1999,2012)$ four main problems have been underlines from these traditional decomposition techniques. To go over these problems and provide a unique theoretical framework, Shorrocks (1999) resorts to an instrument of cooperative game theory, the Shapley value, and demonstrates that this approach permits to derive a good number of decomposition results. We would present the decomposition based on the Shapley value.

\section{Shapley-shamrocks' inequality decomposition}

Let $I$ be the statistical indicator which value is determined by a series of $n$ contributory factors $X_{i}$, with $i \epsilon N=$ $\{1,2, \ldots, n\} . I=f\left(X_{1}, X_{2}, \ldots, X_{n}\right)$, where $f$ describes the model to examine, for example if $I$ is the overall level of inequality then $X_{i}$ will be the contributing factors to inequality. Thereafter, it is assumed that effects of all other factors influencing the variation of $I$ are eliminated. $V(S)$ is used to denote the value that $I$ takes when the $X_{i}, i \notin S$ factors have been omitted.

It is appropriate to characterize the structure of the model $\langle N, V\rangle$ in terms of the sequence of indices of the factor $N$ and the function $F:\{S / S \subseteq N\} \rightarrow \mathbb{R}$, as the sequence of indices of factors contribute to $I$ completely and it would be appropriate to ensure that $V(\varnothing)=0$. In other words $I$ is zero when all factors are removed.

A decomposition of $\langle N, V\rangle$ is a sequence of real values, with $i \in N$ indicating the contribution of each factor. A rule of decomposition $D$ is a function that generates a sequence of contribution factor $C_{i}=C_{i}(N, V)$, with $i \in N$ for every possible model of $\langle N, V\rangle$.

According to Shorrocks (1999) this decomposition should satisfy the properties of symmetry (or anonymity), and accuracy of the decomposition. In the process of establishing the rule of Shapley decomposition, we will consider two possibilities:

The first possibility would be to consider the contribution of each factor at its marginal impact $M_{i}(N, V)=V(N)-$ $V(N-i)$; with $i \in N$. This rule is symmetrical, but does not meet the accuracy requirements of the decomposition. The second possibility is to consider the marginal impact of each factor when they are removed sequentially. Let $\sigma=\left(\sigma_{1}, \sigma_{2}, \ldots, \sigma_{n}\right)$, indicating the order in which factors are left out, and let $S\left(\sigma_{r}, \sigma\right)=\left\{\sigma_{k} \backslash k>r\right\}$ which is the result of the remaining factor after factor $\sigma_{r}$ has been subtracted. Thus the marginal impact is given by:

$$
C_{i}^{\sigma}=V[S(i, \sigma) \cup\{i\}]-V[S(i, \sigma)]=\Delta_{i} V[S(i, \sigma)] ; \forall i \in N
$$

Where $\Delta_{\mathrm{i}} V[S(i, \sigma)]$ is the marginal effect resulting from the addition of factor $i$ to $S$. Shorrocks (2012) subsequently demonstrated that $\sum_{i \in N} C_{i}^{\sigma}=V(N)$, which allows us to assert that the decomposition of $I$ is exact.

However the value of the contribution assigned to any given factor depends on the order in which the factors appear in the sequence $\sigma$ disposal, and the factors are treated symmetrically. This type of problem is solved by considering the possible elimination of $n$ ! sequences denoted by $\Sigma$ and then by calculating the expected value of $C_{i}^{\sigma}$ when the sequences in $\Sigma$ are chosen randomly. This generates the rule of Shapley-Shorrocks decomposition given by:

$$
C_{i}^{S}(N, V)=\sum_{S=0}^{n-1} \sum_{\substack{S \subseteq N \backslash \\|S|=s}}(i) \frac{(n-s-1) ! s !}{n !} \Delta_{i} V[S]
$$

$|S|$ is the cardinality of $S$.

The application to the Gini index of inequality when considering population groups or income sources, allows for the decomposition into sub groups and income sources. The determination of groups or sources is conducted using a sequential elimination procedure.

The sub groups' decomposition has two steps. The first one is to decompose total inequality into inter-group and intra-group contributions. The second step consists in decomposing total intra-group inequality as a sum of group inequality. To do this, we proceed systematically simply by replacing the revenues of those in a group by the average income of that group, such as to eliminate the intra-group contribution of a given group. 
The decomposition by sources with the Shapley-Shorrocks approach supposes that the contribution of component $i$ to total inequality is the expected value of its marginal contribution when it is added randomly to anyone of the various subsets of components that one can choose from the set of all components. When a component is missing from that set, we assume that the observation values of that component are everywhere replaced by its average.

The Shapley value of each component $i$ corresponds therefore to the mean of its marginal contributions. To determine the relative contribution of factor $i$, it suffices to divide the Shapley value by total inequality, as follows:

$$
\varphi_{i}=\frac{C_{i}^{S}(N, V)}{I}
$$

$\varphi_{i}$ represents the relative contribution of the source $i$ to inequality $I$.

\section{Inequalities of Cameroonian Households between 1996 and 2007}

\subsection{Presentation of Data}

The data bases that we will be used to illustrate our theoretical developments are part of the first economic and financial program supported by a Structural Adjustment Facility (SAF) of IMF adopted in 1995. This program has allowed the realization in 1996 of the first Cameroon Household Consumption Survey (ECAM I), on a sample of 1728 households. This partnership was renewed five years later in October 2000, in one of the entry in component C "improving information on poverty" Project Partnership between Public and Private Sector Growth and Reduction poverty (PPPCRP), with the aim to achieve in 2001, the Second Cameroon Household Consumption Survey (ECAM II). The second survey among Cameroonian households covered 10,992 households. As part of monitoring and evaluating the implementation of the Poverty Reduction Strategy (PRS) and measuring progress towards achieving the Millennium Development Goals (MDGs), the Government through the National Institute of Statistics (NIS), achieved in 2007 the Third Cameroon Household Consumption Survey with more than 11,300 households (ECAM III).

The variables we will extract from these data bases concern consumption expenditures of household for the analysis of sources of income / expense and "sociodemographic" characteristics of household heads such as age, sex, area of residence and educational level. It is worthy to note that the ECAM I data base, less elaborate than ECAM II and ECAM III has only nine variables relative to consumption expenditures as opposed to twelve variables in ECAM II. These expenditures were evaluated by household; it is then evident that the number of individuals per household is heterogeneous. Therefore there is a need to consider instead household per capita expenditure, in order to have information on the expenditure of an individual in a household.

To facilitate the analysis of the evolution of inequality in Cameroon on the period from 1996 to 2007, re-treatment of data appears necessary to render information relative to expenditures of household compatible in the period under study. To do this, let us take into consideration only expenditure variables present in the three surveys. This step leaves us with seven variables of household expenditure namely: food expenditure per head (Food), clothing expenditure per head (Clothing), lodging expenditure per head (Lodging), health expenditure per head (Health), transport and communication expenditures per head (Transport), education expenditure per head (Education), leisure expenditure per head (Leisure).

To perform our calculations, we use the Excel software of Microsoft office 2007 and SPSS 13 software. Thereafter, we will use the DAD 4.5 software « Distributional Analysis-Analyses Distributives » (developed by researchers of the University of Laval) to calculate the level-wide and dynamic contributions of global income inequality and the contributions of each income source to total inequality.

\subsection{Presentation of Results}

The set of results issued from the aforementioned approach is presented in three tables: 
Table 1. Inequality indices of Gini for the four variables: 1996, 2001 and 2007

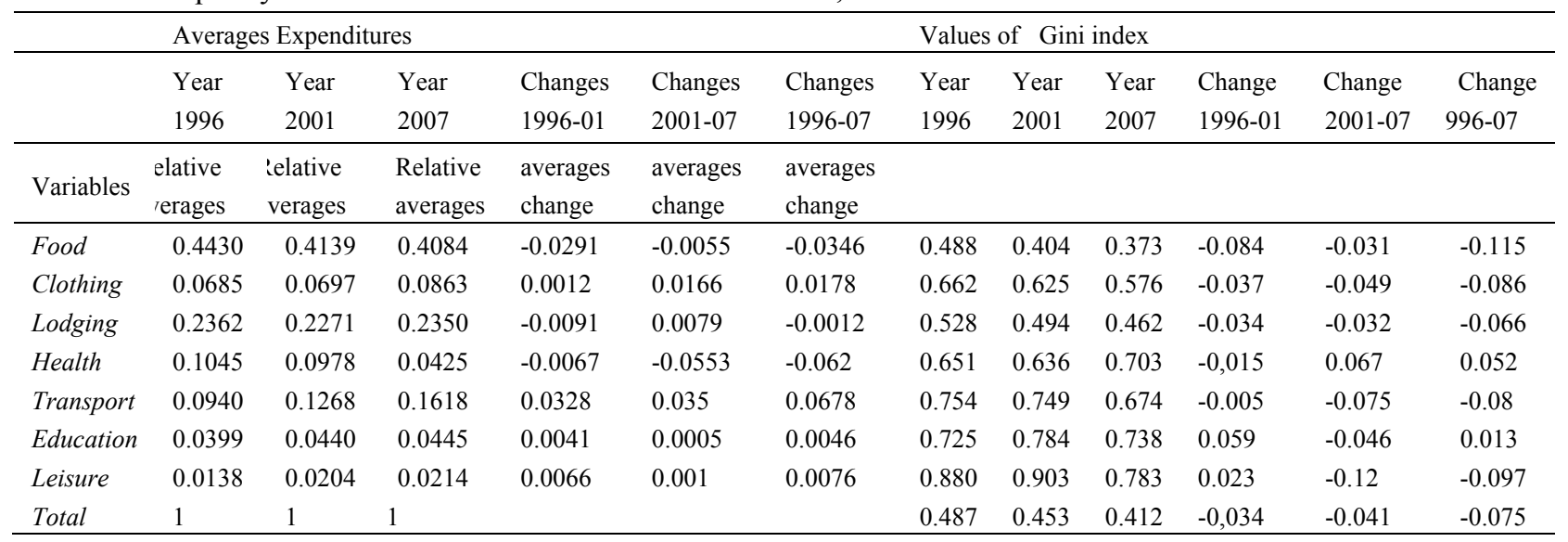

Table 1 displays the inequality indices of Gini for the seven (7) variables as well as their average values and the observed changes at this level for the three periods of reference. The analysis of table (1) reveals that consumer spending over the period of analysis are devoted to about $40 \%$ on food, contrary to spending on leisure which represent less than $1 \%$ of household expenditures in Cameroon during the period. It is noted that housing costs represent just about $20 \%$ of household expenditure. The remaining expenditures are consecrated to clothing, health, education, transport.

We can observe generally that all the expenditure variables registered an increase between 1996 and 2007. This indicates an amelioration of living standards of Cameroonians between these dates, if we assume that prices have remained stable over the period. Concerning the values of Gini indices associated to our variables, we observe that food expenditure per head; notwithstanding the fact that households consecrate in average a greater portion of their expenditures in it has the smallest Gini value for the three periods (0.488 in 1996, 0.404 in 2001 and 0.373 in 2007).

On the contrary, the leisure expenditure, despite its reduced proportion in average household expenditure has the highest Gini value for the three periods ( 0.880 in 1996, 0.903 in 2001 and 0,783 in 2007). This suggests a tremendous impact of leisure expenditure on the level of total household expenditure inequality. Food expenditure experienced a considerable drop in its index value, from 0.488 in 1996 to 0.377 in 2007.

Table 2. Contributions of variables according to Shapley-Shorrocks attribution rule

\begin{tabular}{lllllll}
\hline & \multicolumn{3}{l}{ Absolute contribution } & \multicolumn{5}{l}{ Relative contribution } \\
\hline Variables & 1996 & 2001 & 2007 & 1996 & 2001 & 2007 \\
\hline Food & -0.020 & 0.078 & -0.077 & $-0,041$ & -0.171 & -0.186 \\
Clothing & 0.079 & 0.071 & 0.061 & 0,163 & 0.156 & 0.149 \\
Lodging & 0.024 & 0.015 & 0.015 & 0,049 & 0.034 & 0.035 \\
Health & 0.074 & 0.075 & 0.090 & 0,151 & 0.165 & 0.219 \\
Transport & 0.117 & 0.129 & 0.116 & 0,239 & 0.285 & 0.281 \\
Education & 0.087 & 0.105 & 0.092 & 0,179 & 0.231 & 0.224 \\
Leisure & 0.126 & 0.136 & 0.114 & 0,259 & 0.299 & 0.279 \\
Total & 0.487 & 0.453 & 0.412 & 1 & 1 & 1 \\
\hline
\end{tabular}

Table 2 presents the contributions of different variables according to the shapley-shorrocks attribution rule. The table shows that over the period, the sources of income / expenses that contribute least to the level of inequality is the total power expenditure (- 4.1\% in 1996, 17\% in 2001 and -18.6\% in 2007), while spending on leisure, as we announced earlier have the highest level of contributions to total inequality (25.9\% in 1996, 29.9\% in 2001 and 27.9\% in 2007).

Food expenditure contributes the smallest in average to total inequality, more so its contribution is negative, which indicates that food expenditure contributed to reduce the global level of inequalities. On the contrary, leisure expenses contributed heavily to the observed level of total inequality. 
Table 3. S-Gini Decomposition by Groups (Inequality)

\begin{tabular}{|c|c|c|c|c|c|c|c|c|c|c|c|c|c|c|c|c|c|c|c|}
\hline & \multicolumn{19}{|c|}{ Decomposition to the between \& within Group Components } \\
\hline & \multicolumn{6}{|c|}{ Between Group } & \multicolumn{7}{|c|}{ Within Group } & \multicolumn{6}{|c|}{ Decomposition of the Within Group Component } \\
\hline & \multicolumn{3}{|c|}{ Absolute value } & \multicolumn{3}{|c|}{ Relative value } & \multicolumn{2}{|c|}{ Absolute value } & \multicolumn{4}{|c|}{ Relative value } & \multirow[b]{2}{*}{ Subgroups } & \multicolumn{2}{|c|}{ Absolute value } & \multicolumn{4}{|c|}{ Relative value } \\
\hline & 1996 & 2001 & 2007 & 1996 & 2001 & 2007 & 1996 & 2001 & 2007 & 1996 & 2001 & 2007 & & 1996 & 2001 & 2007 & 1996 & 2001 & 2007 \\
\hline \multirow[t]{2}{*}{ SEX } & \multirow[t]{2}{*}{0.010} & \multirow[t]{2}{*}{0.001} & \multirow[t]{2}{*}{0.001} & \multirow[t]{2}{*}{0.020} & \multirow[t]{2}{*}{0.001} & \multirow[t]{2}{*}{0.003} & \multirow[t]{2}{*}{0.477} & \multirow[t]{2}{*}{0,453} & \multirow[t]{2}{*}{0.410} & \multirow[t]{2}{*}{0.980} & \multirow[t]{2}{*}{0.999} & \multirow[t]{2}{*}{0.997} & & & 0.347 & 0.305 & 0.808 & 0.767 & 0.740 \\
\hline & & & & & & & & & & & & & Women & 0.084 & 0.106 & 0.106 & 0.172 & 0.232 & 0.257 \\
\hline \multirow{3}{*}{ AREAS } & \multirow{3}{*}{0.121} & \multirow{3}{*}{0.103} & \multirow{3}{*}{0.094} & \multirow{3}{*}{0.248} & \multirow{3}{*}{0.227} & & & & & & & & Urban & 0.276 & 0.191 & 0.201 & 0.566 & 0.422 & 0.487 \\
\hline & & & & & & 0.229 & 0.366 & 0.350 & 0.317 & 0.752 & 0.773 & 0.771 & Semi-urban & 0.020 & 0.062 & 0.032 & 0.041 & 0.137 & 0.078 \\
\hline & & & & & & & & & & & & & Rural & 0.071 & 0.097 & 0.085 & 0.146 & 0.214 & 0.206 \\
\hline & & & & & & & & & & & & & No education & 0.075 & 0.078 & 0.065 & 0.154 & 0.172 & 0.158 \\
\hline FDU А АTON & 0144 & 0129 & 01210 & & 0285 & 0204 & 032 & 0327 & - & 0.704 & 0774 & 0706 & primary education & 0.093 & 0.099 & 0.094 & 0.191 & 0.218 & 0.228 \\
\hline$E D U C A T I O N$ & 0.144 & 0.129 & 0.1210. & & 0.283 & 0.294 & 0.343 & 0.324 & 0.291 & 0.104 & 0.114 & 0.100 & secondary education & 0.140 & 0.117 & 0.108 & 0.287 & 0.258 & 0.261 \\
\hline & & & & & & & & & & & & & higher educational level & 0.035 & 0.0299 & 0.024 & 0.073 & 0.066 & 0.059 \\
\hline & & & & & & & & & & & & & {$[0-21[$} & 0.004 & 0.008 & 0.014 & 0.008 & 0.019 & 0.034 \\
\hline & & & & & & & & & & & & & {$[21-31[$} & 0.078 & 0.086 & 0.085 & 0.160 & 0.189 & 0.205 \\
\hline & & & & & & & & & & & & & {$[31-41[$} & 0.138 & 0.108 & 0.100 & 0.284 & 0.239 & 0.242 \\
\hline$A G E$ & 0.059 & 0.048 & 0.039 & 0.122 & 0.106 & 0.095 & 0.428 & 0.405 & 0.372 & 0.878 & 0.893 & 0.905 & {$[41-51[$} & 0.099 & 0.088 & 0.085 & 0.204 & 0.195 & 0.206 \\
\hline & & & & & & & & & & & & & [51-61[ & 0.069 & 0.067 & 0.049 & 0.143 & 0.148 & 0.118 \\
\hline & & & & & & & & & & & & & [61-100[ & 0.039 & 0.047 & 0.041 & 0.080 & 0.104 & 0.098 \\
\hline
\end{tabular}

Table 3 is dedicated to the decomposition of inequality by subgroups. As announced earlier, we selected subgroups for gender of household head, area of residence, educational attainment and age of household head. The overall pattern that emerges shows a strong involvement of the within group component to total inequality over the entire study period. This reflects the fact that inequality is much explained by observable characteristics within the groups. This component of the intergroup gradually decreases over the period in favor of the within group component. The decomposition of the latter could provide an explanation to this global trend.

The analysis of the within group by gender reveals that there is a wide dispersion of consumer spending between householders male, since the inequality between men heads of households over the period contributes more than 0.73 to the inequality of within group, while the female heads of households contribute less than 0.26 in the within group inequality. However, there is a decrease in inequality within households which are headed by a man (whose relative contributions increased from 0,808 in 1996 to 0.74 in 2007), and an increase in inequality in consumption of household heads females (including the relative contributions of 0172 passed in 1996 to 0,257 in 2007).

The decomposition of the within group by place of residence can show that the inequality is very pronounced among heads of households living in urban areas throughout the study period. The contribution of household heads in rural areas is less important. Consumption expenditure of household heads in urban areas accounted for most of the component of the within group. However, there is an increase in inequality in rural areas and falling out inequality in urban areas. Inequality observed in semi urban areas are the lowest.

The decomposition of the within group by level of education shows that heads of households who have an education level corresponding to primary and secondary levels contribute about $50 \%$ at the within group component. It is these categories that account for most of the inequality of within group when the break occurs according to the level of education. Household heads with an educational level equivalent to higher education have an income level slightly more homogeneous than the other categories.

The decomposition of the within group according to age groups shows that heads of household aged under 21 have distributions of consumption expenditure as homogeneous over the period. The strong dispersions observed in the cutting age are attributable to consumption expenditure of household heads aged between 31 and 50 .

\section{Conclusion}

The objective of this study was to evaluate the evolution of inequality of consumption expenditures of households in Cameroon over the period 1996-2007. The developments carried out in this study have enabled us to note that, beyond the fact that the literature on the conceptualization and measurement of inequality is rich and varied. The application of the Shapley value to analyse inequalities by sources and by subgroup presents interesting properties. In fact, one of the advantages of this value is that it possesses a good number of characteristics that permit its application in diverse domain where there is the question of coalition and share. 
From the results of our study, we can generally conclude that, on the one hand, food expenditure on average contributes less to total inequality, more so the contribution of this source has a negative sign, indicating that it has contributed to reduce global inequalities. On the other hand, leisure expenses contribute strongly to the observed total inequality and we observe from table 2 that the decrease in total inequality of the study period is largely explained by food expenditure. Food and lodging expenses appear to be vital in the explanation of inequalities by source of expenditure in Cameroon.

Decomposition by subgroup has revealed that the within group explains just about $70 \%$ of the inequality observed in decompositions by gender, area of esidence, educational level and age. The decomposition of the within group shows that the dispersion of consumer spending for male household heads is larger than for women heads of households. Householders living in urban areas concentrate the greater dispersion of expenditure. Household heads with an educational level equivalent to higher education appear to have a more homogeneous structure of expenditure, while the strong dispersion observed in the distribution by age is explained by the expenditures of household heads aged between 31 and 50 .

\section{References}

Baye, M. F. (2005). Alternative methods for setting poverty lines; measuring poverty in Cameroon. Pakistant Economic and Social Review, 43(1), 17-42.

Bourguignon, F. (1979). Decomposable Income Inequality Measures. Econometrica, 47, 901-920. http://dx.doi.org/10.2307/1914138

Bourguignon, F., \& Morrisson, C. (2002). Inequality among World Citizens: 1820-1992. American Economic Review, 92(4), 727-44. http://dx.doi.org/10.1257/00028280260344443

Chameni, N. C. (2005). A three components subgroup decomposition of the Hirschman-Herfindahl index and ousehold's income inequalities in Cameroon. Applied Economics Letters, 12, 941-947. http://dx.doi.org/10.1080/13504850500377959

Chameni, N. C. (2008). The "natural" bidimensional decomposition of inequality indices: evaluating factors contribution to households welfare inequality in Cameroon, 1996-2001. Applied Economics Letters, 15, 963-970. http://dx.doi.org/10.1080/13504850600972311

Chantreuil, F., \& Trannoy, A. (1999). Inequality Decomposition Values: The tradeoff between marginality and consistency. DP Thema, 99-124.

Direction de la Statistique et de la Comptabilité Nationale (DSCN). (1996). Enquête Camerounaise auprès des Ménages: éléments méthodologiques. Document de travail.

DSCN. (2001). Rapport Enquête Camerounaise auprès des Ménages. Document de travail.

Dubois, J-L. (2000). Comment les politiques de lutte contre la pauvreté prennent-elles en compte les inégalités sexuées? Genre, population et développement, les pays du Sud, (Th. Locoh, ed.), Dossiers et recherches de l'INED Paris, 85, 35-51.

Duclos, J.Y., Araar, A., \& Fortin, C. (2006). DAD: un logiciel pour l'analyse distributive, MIMAP program, centre international pour la recherche et le développement.

Fambon, S. (2005). Economic Growth, Poverty and Income Inequality in Cameroon. Revue d'économie du developpement, 05(1), 91. http://dx.doi.org/10.3917/edd.191.091

Fambon, S. (2006). Poverty Profiles for Cameroon. AERC discussion paper, Poverty, Income Distribution and Labour Markets in Sub-Sarahan Africa Dissemination Conference 12-13 October, 2006, Addis Ababa, Ethiopia.

Fei, J. C. H., Ranis, G., \& Kuo, S. W. Y. (1978). Growth and the family distribution of income by factor components. Quaterly Journal of Economics, 92, 17-53. http://dx.doi.org/10.2307/1885997

Lemel, R. Y. (1991). Stratification et mobilité sociale. Colin, Paris.

Mussard, S. (2004). The bidimensional decomposition of the Gini ratio. A case: Italy. Applied Economics letters, 11, 503-505. http://dx.doi.org/10.1080/1350485042000244530

Mussard, S., \& Pi Alperin, M. N. (2008). Inequality in multidimensional poverty: evidence from Argentina, Applied Economics Letters, 15, 759-765. http://dx.doi.org/10.1080/13504850600770988

National Institute of Statistics (NIS). (2008). Report ECAM III, Ministère de l'Économie et de la Planification et de l'Aménagement du Territoire (MINEPAT). 
Owen, G. (1977). Value of games with a priori union in mathematical economics and game theory; Essays in honour of Oskar Morgenstern. Henn, R., Moeschlin (springer-vertag, Berlin-Heidelberg-New-York).

Pyatt, G., Chen, C., \& Fei, J. (1980). The distribution of income by factor components. Quarterly Journal of Economics, 95, 451-474. http://dx.doi.org/10.2307/1885088

Rao, V. M. (1969). Two decompositions of concentration ratio. Journal of the royal statistical Society, 132, 418-425. http://dx.doi.org/10.2307/2344120

Sastre, M., \& Trannoy, A. (2002). Shapley inequality decomposition by factor components WP.T. 6(1).

Shorrocks A. F. (1984). Inequality Decomposition by Factor Components and by Population Subgroups. Econometrica, 53, 1369-1386. http://dx.doi.org/10.2307/1913511

Shorrocks A. F. (2012). Decomposition Procedures for Distributional Analysis: A Unified Framework Based on the Shapley Value. Journal of Economic Inequality. http://dx.doi.org/10.1007/s10888-011-9214-z

Shorrocks, A. F. (1980). The class of additively decomposable inequality measures. Econometrica, 48, 613-625. http://dx.doi.org/10.2307/1913126

Shorrocks, A. F. (1982). Inequality decomposition by factor components. Econometrica, 50, 193-211. http://dx.doi.org/10.2307/1912537

Shorrocks, A. F. (1999). A decomposition procedure for distributional analysis; a unified framework based on Shapley value. University of Essex and Institute for fiscal studies, Mimeo.

Tocqueville, A. de. (1961). de la démocratie en Amérique. Paris, Gallimard.

Walzer, M. (1983). Spheres of Justice. A Defense of Pluralism and Equality. New York : Harper Collins Publishers, trad. de P. Engel, Sphères de Justice, une défense du pluralisme et de l'égalité, Paris: Edition du Seuil.

\section{Notes}

Note 1. Chameni (2005) proposed a new decomposition in sub-groups of the Hirschman-Herfindahl index in three components: intra group, net inter group and over-lapping inter group, before proposing a simultaneous decomposition in sub group and in income source.

Appendices

The Shapley value applied to the analyses of inequalities by sources highlights the following remarks:

Remark 1: according to Shorrocks (1999), the contribution of Shapley for an income source equally distributed is zero. Consequently, source inequalities are equal and the contribution of these sources to total inequality is zero. This is clearer when the inequality index used is an absolute index as the variance. This problem is resolved by using relative inequality indices as the Gini index or the square of the coefficient of variation. But these relative indices give negative marginal contributions. This proposal justifies the fact that in the configuration of a game that treats inequality by equalised source, relative indices be preferred over absolute indices.

Remark 2: according to Chantreuil and Trannoy (1999), the relative Gini index when applied to the attribution of source contributions to total inequality, for Shapley, games having equalitarian distribution of some sources do not coincide with the decomposition of the Gini index as it attributes always zero contributions to sources distributed equally. However, it is important to note that the inequality decomposition of Shapley using variance as inequality index is nothing other than the natural decomposition of the variance.

These remarks have permitted the elaboration of a set of strong criticisms against the Shapley-shorrocks and its applicability to the analysis of inequality by sources, criticisms that can be found in summary in the article of Sastre and Trannoy (2002). The latter proposes the nested form of Shapley decomposition basing on the extensions brought by Owen (1977) to the original value of Shapley. 